\title{
An idea of small-light weight joint actuator for lower limb brace
}

○ 山本耕之 正(久留米工大), 元田英一 正，鈴木康婎 正(労リハエセンター)

Kouji Yamamoto, Kurume Institute of Technology, 2228 Kamitsu Kurume, Fukuoka830-0052, Japan

Eiichi Genda, Yasuo Suzuki, Rousai Rehabilitation Engineering Center, 1-10-5 Komei-cho Minato-ku Nagoya 455-0018 Japan

Key Words: lower limb brace, joint articulator, high-ratio reduction, sandwich style planetary gear layers

\section{1 緒震}

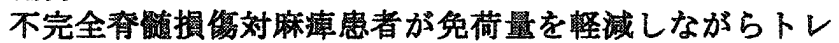
ッドミル上の長期歩行部練で. 歩行能力を回復する例を胃 る. またこの剖練の前にストレッチ遛動を行うと剖練の効 果が上がることが分かっている. ストレッチと歩行を補助 するためのロボットやパワースーツは未だ高洒な上, 重装 倩であるので，多数を漼偖し患者全てが同時に使うことが できず，結局は社会復煟の障害となっている。ここに小径 の落型軽嚳な自立駆動関艒を持つ安価な下肢装具があれば, 訓練を受ける人々にもセラピストにも朗報となる.

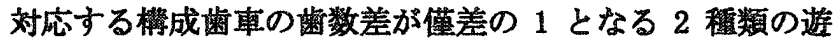

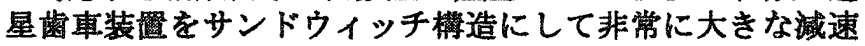
比の関節装绦を，小型モーターで駆動し，下肢関節モーメ

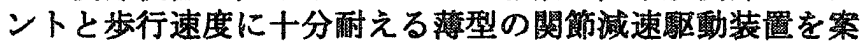
出した。 その原理とこれを関節ニニットとして組み込んだ 下肢装具を提案する。

\section{2 減速機構の原理}

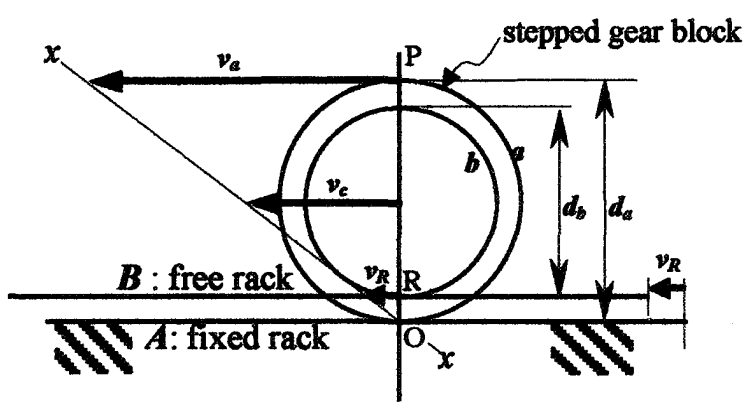

Fig.1 Stepped gear rotation's slow rack conveying

図 1 には減速原理を示した. 大小各々 $a, b 2$ 段の段付き齿 車の各段と略み合う 2 つのラック $A, B$ を上下平行に配㹂 ᄂ. 固定ラック $A$ 上で段付き歯草が回転すると, ラック $\boldsymbol{B}$ は $v_{R}$ の速度で移動する. この時 $a$ 菌車上死点 $\mathrm{P}$ の速度 $v_{a}$ と の比は 0 点を瞬間中心として, 2 つの歯車 $a, b$, のモジュー ルを等しく, ピッチ円直径は $d_{a} d_{b}$. 歯数を $z_{a} z_{b}$ とし, 歯数 $z_{a}-z_{b}$ の差を最小值 1 とすると減速比は最大となる.

$$
\begin{array}{r}
v_{R} / v_{a}=\overline{\mathrm{OR}} / \overline{\mathrm{OP}} \ldots \ldots . \\
v_{R}=\left(\frac{d_{a}-d_{b}}{2 d_{a}}\right) v_{a}=\left(\frac{z_{a}-z_{b}}{2 z_{a}}\right) v_{a}=\left(\frac{1}{2 z_{a}}\right) v_{a} .
\end{array}
$$

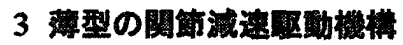

2 個のラックをリング状にして大小 2 個の同心の内輠車 $A$

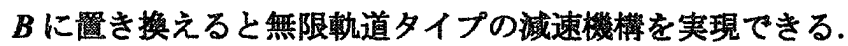
これを $A, B, A$ とサンドウィッチ状に重ね関節を形成する装 整の概念を図 2 に示した。

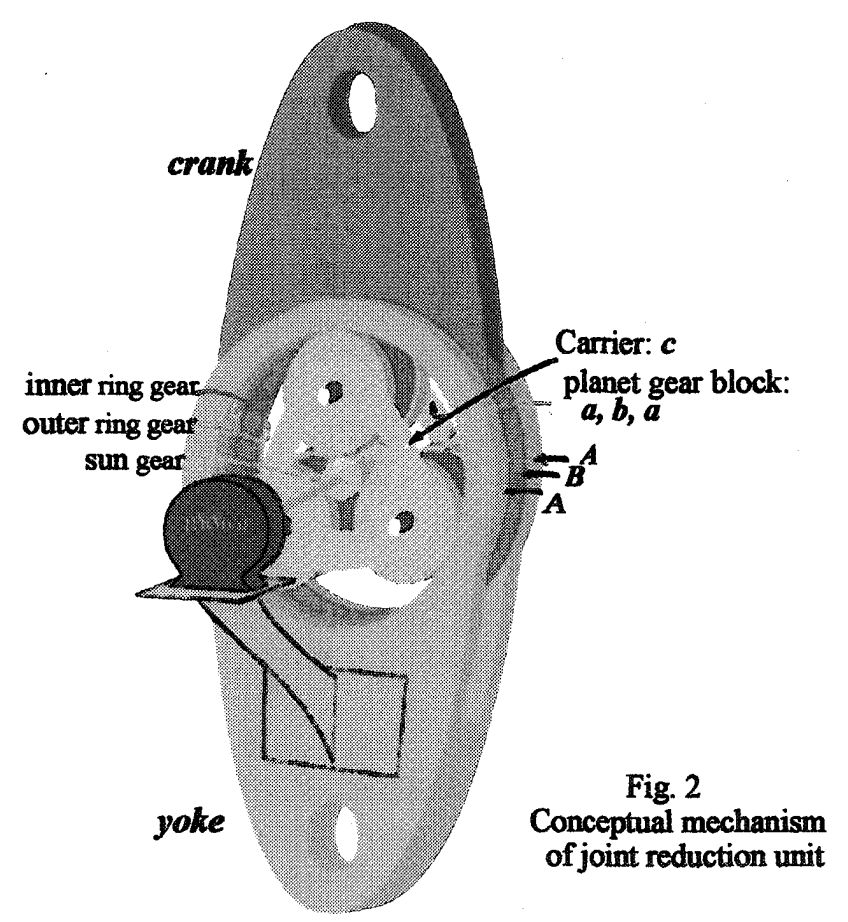

ヨークと一体の外屡 $A$ は大径 2 個の完全遊星端車列で歯 数 $\mathrm{z}_{\mathrm{g}}$ の太晹齿車 $\mathrm{s}$ を持ち，キャリヤー (アーム) c で等角度 にリング内に 3 個配虚した段付遊星淗車の大径側と烸み合 う.この 2 屬がクランクと一体の太陽歯車を持たない不完 全遊星齿車列を挟むサンドイッチをなす，段付き目專とラ

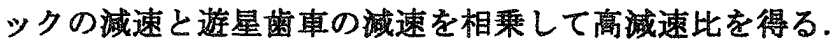

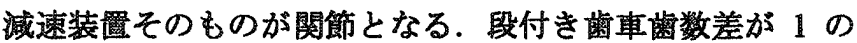
とき，リング状内歯車の歯数を $z_{A}, z_{B}$ として崡数差は

$$
\begin{aligned}
& z_{A}=z_{s}+2 z_{a}, \quad z_{B}=z_{s}+1+2 z_{b} \\
& z_{A}-z_{B}=-1+2\left(z_{a}-z_{b}\right)=1, \quad z_{a}-z_{b}=1 .
\end{aligned}
$$

\begin{tabular}{|c|c|c|c|c|c|c|c|}
\hline \multirow{2}{*}{\multicolumn{2}{|c|}{ Parts }} & \multirow{2}{*}{$\begin{array}{l}\text { s: sun gear } \\
\text { motor shaft }\end{array}$} & $a$ : planet gear & $b$ : planet gear & \multirow{2}{*}{$\begin{array}{l}\text { B:minor internal } \\
\text { ring gear }\end{array}$} & \multirow{2}{*}{$\begin{array}{l}\text { A: major internal } \\
\text { ring gear }\end{array}$} & \multirow{2}{*}{$\begin{array}{l}\text { c: Carrier } \\
\text { (Arm) }\end{array}$} \\
\hline & & & \multicolumn{2}{|c|}{ in one block as a stepped gear } & & & \\
\hline & Tooth number & $z_{8}=18$ & $z_{3}=45$ & $\mathrm{z}_{\mathrm{b}}=44$ & $\mathrm{z}_{\mathrm{B}}=107$ & $z_{A}=108$ & \\
\hline $\operatorname{mot}$ & on revolution & $\mathrm{N}_{\mathrm{s}}$ & $\mathrm{N}_{\mathrm{a}}$ & $\mathrm{N}_{\mathrm{b}}$ & $\mathrm{N}_{\mathrm{B}}$ & $N_{A}$ & $\mathrm{~N}_{\mathrm{c}}$ \\
\hline & $\begin{array}{l}\text { carrier fixed, sun gear rotates } \\
\text { clockwise } 1 \text { turn }\end{array}$ & 1 & $\begin{aligned} &-N_{8} z_{8} / z_{B} \\
&--2 / 5\end{aligned}$ & $=\begin{array}{l}-\mathrm{N}_{\mathrm{B}} \mathrm{z}_{\mathrm{g}} / \mathrm{Z}_{\mathrm{R}} \\
-2 / 5\end{array}$ & $\begin{aligned} & -\mathrm{N}_{\mathrm{s}}\left(\mathrm{z}_{\mathrm{B}} / \mathrm{z}_{\mathrm{B}}\right)\left(\mathrm{z}_{\mathrm{b}} / \mathrm{z}_{\mathrm{B}}\right) \\
= & -(2 / 5)(44 / 107)\end{aligned}$ & $\begin{aligned}= & -\mathrm{N}_{\mathrm{s}} \mathrm{Z}_{\mathrm{s}} / \mathrm{z}_{\mathrm{A}} \\
= & -18 / 108\end{aligned}$ & 0 \\
\hline II & whole rotates clockwise 1 turn & 1 & 1 & 1 & 1 & 1 & 1 \\
\hline III & $\begin{array}{l}\text { carrier fixed, A gear rotates unti- } \\
\text { clockwise } 1 \text { tum }\end{array}$ & $\begin{array}{l}108 / 18 \\
6\end{array}$ & $\begin{array}{l}-108 / 45 \\
-12 / 5\end{array}$ & $\begin{array}{l}-108 / 45 \\
-12 / 5\end{array}$ & $\begin{array}{l}-(108 / 45)(44 / 107) \\
-4752 / 4815\end{array}$ & -1 & 0 \\
\hline IV & Total of $\mathrm{II}+\mathrm{III}$ & $1+6=7$ & $1-12 / 5=-7 / 5$ & $1-12 / 5=-7 / 5$ & $1-4752 / 4815$ & 0 & 1 \\
\hline & final reduction ratio & inpuest: 1 & $-1 / 5$ & $-1 / 5$ & output: $1 / 535$ & 0 & $1 / 7$ \\
\hline
\end{tabular}

Table 1 Gear tooth numbers and reduction ratios calculation 


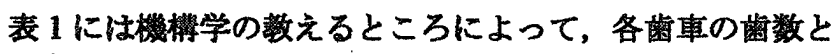
各条件回転に対する各蔽車の回枟数とさらにモーター軸と 闺節回転との終減速比を算出した。

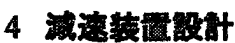

\section{4-1 曹霜の寸法と強度}

この関節駆趿の大きさの制約柱，モジュールをスリムで 䔦型とすることから決まる.モーターの突出分も考路して， 実㻮の外径はおおよそ $100[\mathrm{~mm}]$ 以内, 従って, 内齿車のピ シチ内の淔径は歯底の肉原を考慮して $50[\mathrm{~mm}]$ から $60[\mathrm{~mm}]$ とする必要がある，また厚さは 30[mm]以内に納めなければ ならない. 従って 1 層の遊星齿車の崡幅は $5[\mathrm{~mm}]$ 以内に納 めなければならない。

強度については下肢関飾の中最大の歩行中の足関節モー メントに耐えることである.これをおおよそ $M_{a}=70000$ [Nmm] としてこれに酎えるように設計する必要がある. 最 大のリング状内歯車のピッチ円周上の接線力を $P[\mathrm{~N}]$, 面经 ピッチ(module) $m[\mathrm{~mm}]$ をLewis の式を変形して求めると,

$$
\begin{gathered}
P=\sigma_{b} \pi m w y \\
m=\sqrt[3]{\frac{2 M_{a}}{z_{A} \sigma_{b} \pi k y}} \quad \therefore m=0.47 \approx 0.5 \ldots .
\end{gathered}
$$

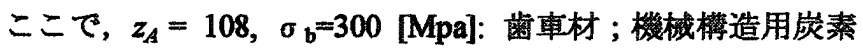
銅 $(0.45 \mathrm{C} \%)$ の許容綝り返し曲げ応力, $w[\mathrm{~mm}]$ ：歯輻, $k=\mathrm{w} / \mathrm{m}$

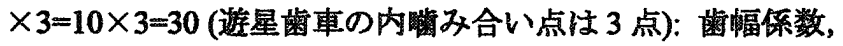
そして $y=0.455$ : 歯形係数とする.

\section{4-2 不宽全遊星檕車の䁬み合い位相の合わせ方}

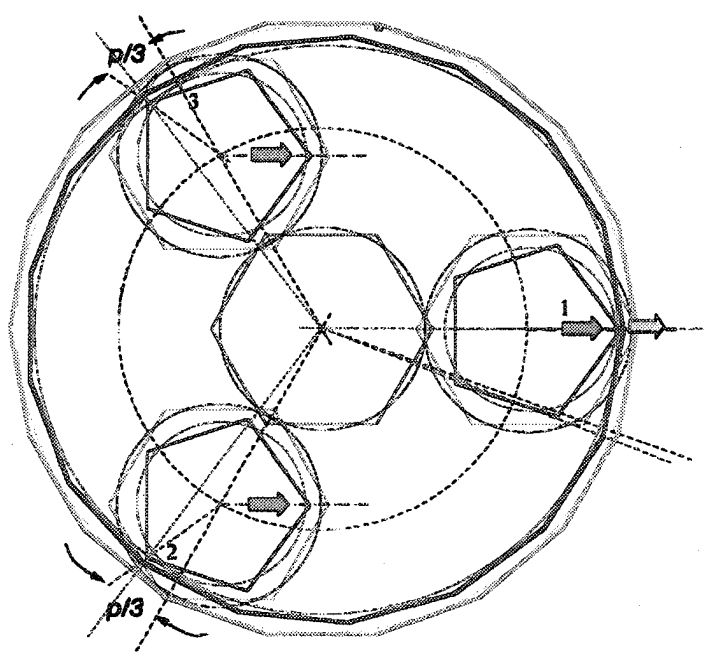

Fig. 3 Planetary stepped gear blocks ${ }^{6}$ tooth phase meshing

サンドウィッチは外側 2 屬の完全遊星崡車列で不完全遊星

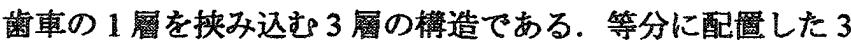
個の遊星歯車ブロックは 3 段の段付き歯車となっている.完

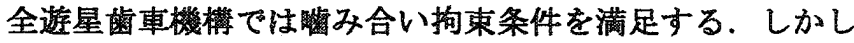

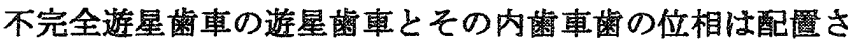
れる位瑥に従ってずれる. 組立てにはこの点に注意を要す。

図 3 にこの解決法を多角形のそデルを用いて示した. 遊 星蔽車を 3 㞗のブロックにするとき一つの歯の向きが一致 するように組み立て，3 個ともこの一致点を同じ问きにして 平行移動し，各位圈に配置すればよい.リング畨車とブロ ック遊星歯車各々では一周当たり 1 齒分のずれであるから 一周の $1 / 3$ の位睓では 1 歯の 1/3 のずれとなってとなって各

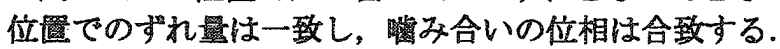

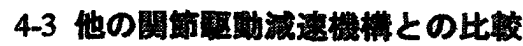

図 4 に示す 2 つの減速方式の比较に示すように，左の八

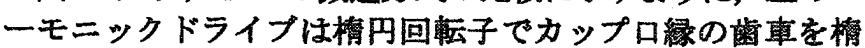
円に㩒ませてリング状内歯車の 2 簀所で接触するため 1 回 転当たり 2 菌分進さが，右は 1 粰のみ進むので減速比は 2 倍大きくとれる. しかもカップの深さのためのスペースを取 る必要がなく, さらに内接点俚 2 ないし 3 簓所以上を取る ことができ齔幅を稳ぐことができるため薄型を追求できる. また特殊カップ型菌車や，他の機粠に見る転移歯重を使用

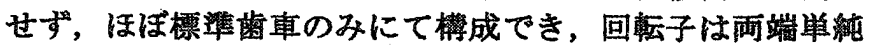
支持なのでスラストや片持荷重からも解放される。

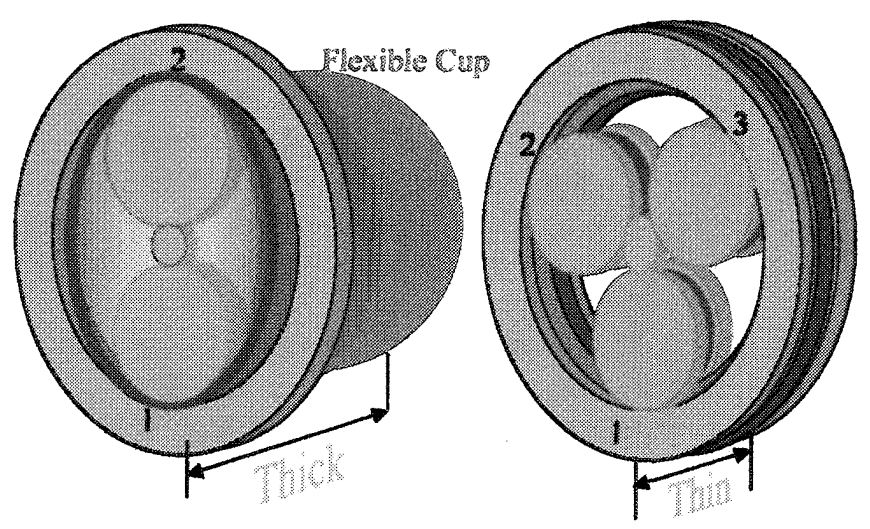

Fig.4 Comparison with the other reduction mechanism

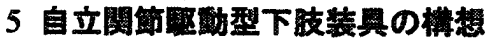

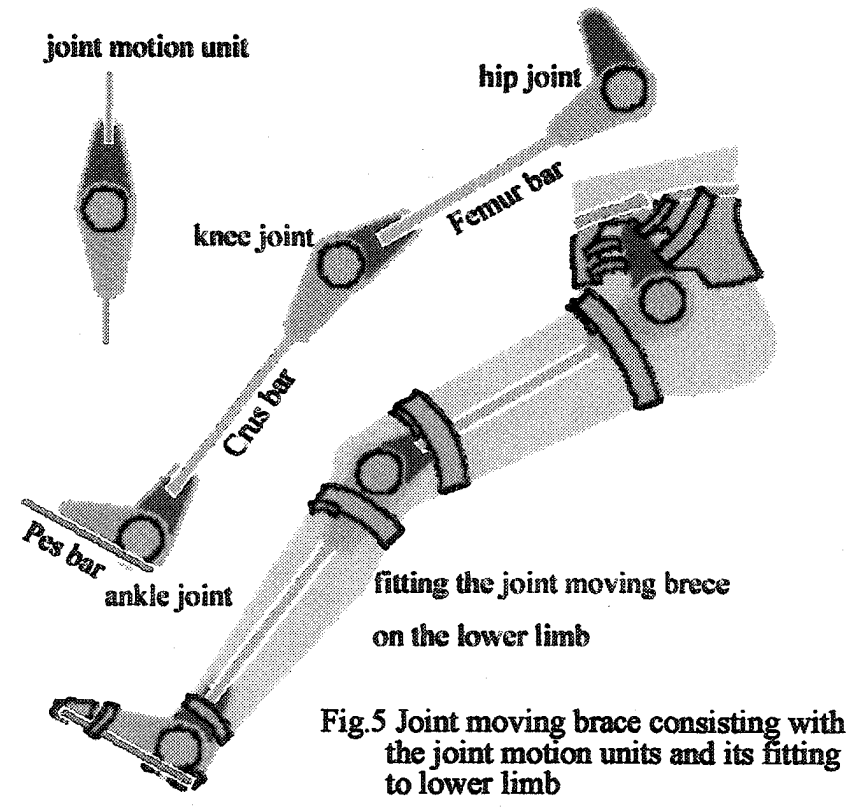

図 5 には本関節隇速駆動装置ニニットを, 全ての関節に 共通に用い，大腿，下腿，足部のバーで連結して下肢装具 を棈成できることを示した，幼児から成人に至る広筑围の 体格に合った装具製作はバーの長さ調節のみで可能となる。

\section{6 䋓絧}

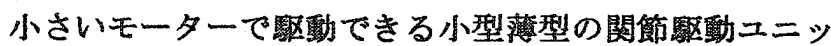
ト用いた自立関節駆動型下肢装具を提案した。将来，歌動モ 一ターの統合制御を付加して，ストレッチからトレッドミ ル上で歩行訓繒を介助代行させることができれば，步行能 力回復訓蟓を授受する双方の人々に朗報となる。 